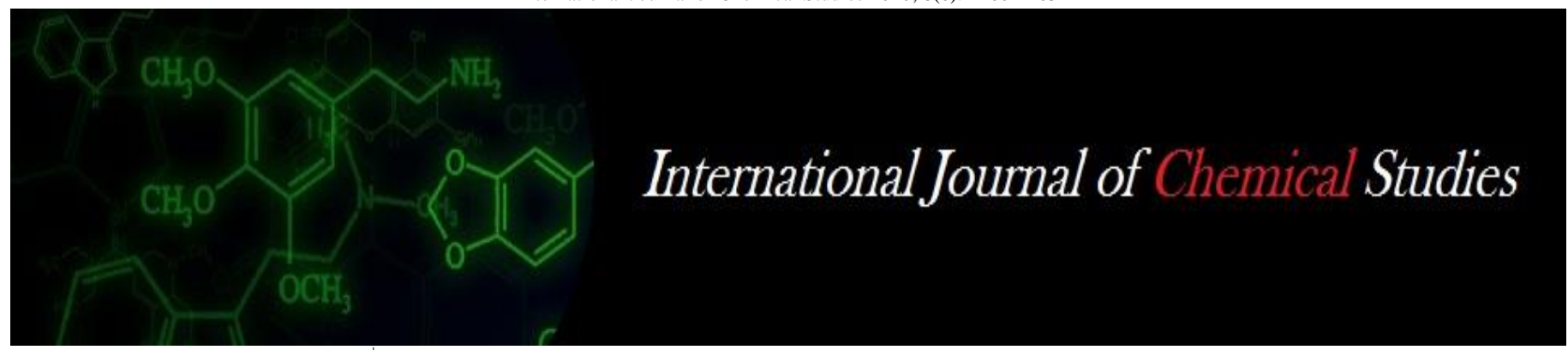

P-ISSN: 2349-8528

E-ISSN: 2321-4902

www.chemijournal.com

IJCS 2020; 8(6): 1160-1163

(C) 2020 IJCS

Received: 20-09-2020

Accepted: 22-10-2020

Bhattacharjee K

Department of Parasitology,

College of Veterinary Science,

Assam Agricultural University,

Khanapara, Guwahati, Assam,

India

Sen $S$.

Faculty of Pharmaceutical

Science, Assam Down Town

University, Panikhaiti,

Guwahati, Assam, India

\section{Dey BK}

Faculty of Pharmaceutical

Science, Assam Down Town

University, Panikhaiti,

Guwahati, Assam, India

\section{Deka DK.}

Department of Parasitology, College of Veterinary Science,

Assam Agricultural University,

Khanapara, Guwahati, Assam,

India

\section{Bora $\mathbf{S}$}

Department of Parasitology,

College of Veterinary Science,

Assam Agricultural University,

Khanapara, Guwahati, Assam,

India

Corresponding Author

Bhattacharjee K

Department of Parasitology,

College of Veterinary Science,

Assam Agricultural University,

Khanapara, Guwahati, Assam,

India

\section{Anthelmintic activity of extracts of Azadirachta indica and Andrographis paniculata and their pharmacological analysis}

\author{
Bhattacharjee K, Sen S., Dey BK, Deka DK. and Bora S
}

DOI: https://doi.org/10.22271/chemi.2020.v8.i6q.10918

\section{Abstract}

The aqueous and methanolic extracts of Azadirachta indica and Andrographis paniculata which were found to have effective anthelmintic properties were subjected to pharmacological analysis. Alkaloids, carbohydrate, amino acid, glycosides, saponin, steroid, flavonoid, tannin and phenolic compounds were present in all the four extracts. Anthraquinone glycosides were present in the extracts of Azadirachta indica. Cardiac glycosides were present only in the methanolic extract of Azadirachta indica whereas triterpenoids were present only in methanolic extract of Andrographis paniculata.

Keywords: Extracts, Azadirachta indica, Andrographis paniculata, pharmacological analysis

\section{Introduction}

Nature has provided a complete store- house of remedies to cure all ailments and related diseases of mankind and animals as well. In the past, almost all the medicines used were extracted from the plants as they have been man's chemist for centuries. Medicinal plants are considered as having great economic value in the Indian subcontinent. Ethno-botanical studies are significantly associated with revealing locally important plant species especially for the discovery of crude drugs. The modern pharmacopoeia still contains $25 \%$ of the drugs derived from plants and many others are synthetic analogues built on prototype compounds isolated from plants. (Muthee et al., 2011). Anthelmintics resistance in parasites which has developed due to the indiscriminate use of commercial anthelimintics commonly used in the treatment of parasitic disease along with the inefficacy of these compounds is threatening the animal health (Bauri et al., 2015) ${ }^{[3]}$. Also, the cost of routine vermifuge applications on herds, the problem of residues in animal products and the environment have prompted research on the anthelmintic activity of plant extracts (Chagas et al, 2008) ${ }^{[4]}$. Phytochemicals present in plants have enormous therapeutic potential and are effective in the treatment of infectious diseases while simultaneously mitigating many of the side effects that are often associated with synthetic compounds. Most diseases caused by helminths are chronic, debilitating in nature, they probably cause more morbidity, greater economic and social deprivation among humans and animals than any other parasites. A number of plants possessing anti parasitic properties are used as potent anthelmintics (Bauri et al., 2015) ${ }^{[3]}$. The World Health Organization (WHO) estimated that $80 \%$ of the population of developing countries rely on traditional medicine mostly plant drugs, for their primary health care needs.

Azadirachta indica A. Juss (syn. Melia azadirachta) is well known in India and its neighboring countries for more than 2000 years as one of the most versatile medicinal having a wide spectrum of biological activity (Susmitha et al., 2013) ${ }^{[12]}$. Andrographis paniculata, Nees. (Kalmegh) is popular worldwide with the name of "King of Bitters" in English. Extracts (crude powder) of the two plants, Azadirachta indica and Andrographis paniculata were considered for the study as they yielded good results in our previous works on herbal anthelmintics. The phytochemical constituents and their standardization are accelerated with the development of instrumental analysis and this field becomes important and new for investigation (Yadav and Singh, 2011) ${ }^{[13]}$. The present study was undertaken to analyze the anthelmintic phytochemicals present in the extracts of two plants namely, A. indica and A. paniculata since no previous works was done on this aspect in this region of the country. 


\section{Materials and Methods \\ Choice of plants}

The leaves of these two plants namely Azadirachta indica and Andrographis paniculata have been extensively used by farmers in Assam to feed their animals (cattle, goat, sheep etc.) due to their natural anthelmintic property.

\section{Selection of plants and preparation of plant powder}

The leaves and stems of the plants were freshly collected from different places ensuring that they were healthy and uninfected. At first, the leaves were washed under running tap water to remove dust and other foreign particles and again washed with distilled water and dried in faint sunlight for a week and then kept in the laboratory. The dried leaves and stems were then crushed to powder in a rotor mixer and kept in air tight containers with proper labelling.

\section{Preparation of organic solvent extract}

For methanolic extract, $50 \mathrm{gm}$ powder from each plant was taken and soaked in $400 \mathrm{ml}$ of the respective solvent and stirred properly after every one hour in clean glass beaker kept at room temperature (Sharma et al., 1971) ${ }^{[11]}$. The mixtures were later filtered through several layers of muslin cloth and using separating funnels. The filtrate was concentrated by evaporation at temperature $\left(40-50{ }^{\circ} \mathrm{C}\right)$ and rotation in a rotary evaporator until the desired volume was obtained

\section{Preparation of aqueous extract}

Powdered extract of $50 \mathrm{gm}$ weight of each plant was soaked in $400 \mathrm{ml}$. of distilled water and stirred every one-hour interval initially for 2-3 times and left undisturbed for $8 \mathrm{hrs}$ at room temp and then filtered through muslin cloth and separating funnel. Then the filtrate was concentrated by evaporation at temp. $\left(50-55{ }^{\circ} \mathrm{C}\right)$ and rotation in a rotary evaporator until the desired volume was obtained.

The extract residues were individually marked, kept in airtight glass bottles in cool and dark place at $4{ }^{\circ} \mathrm{C}$ (refrigerator) for further use.

Phytochemical analysis was carried out for different components following standard procedures.

\section{Test for alkaloids}

- Mayer's test: Few $\mathrm{ml}$ of filtrate +2 drops Mayer's reagent (Potassium mercuric solution) along sides of tube. White or creamy precipitate.

- Hager's test: Few $\mathrm{ml}$ of filtrate +1 or $2 \mathrm{ml}$ of Hager's reagent (Saturated solution of picric acid).Prominent yellow/crystalline yellow ppt.

- Dragendorff's test: Few $\mathrm{ml}$ of filtrate +1 or $2 \mathrm{ml}$ of Dragendorff's reagent (Potassium bismuth iodide solution).Prominent reddish brown/orange red ppt

\section{Test for carbohydrates}

The minimum amount of the extracts was dissolved in $5 \mathrm{ml}$ of distilled water and filtered. The filtrate was subjected to test for carbohydrates.

- Molisch's test: The filtrate was treated with 2-3 drops of $1 \%$ alcoholic alpha naphthol and $2 \mathrm{ml}$ of concentrated sulphuric acid was added along the sides of the test tube. A violet ring at the junction of layers was seen.

- Fehling's test: The filtrate was treated with $1 \mathrm{ml}$ of Fehling's A and B and heated in a boiling water bath for 5-10min. Appearance of reddish orange precipitate shows the presence of carbohydrates.
- Benedict's test: $0.5 \mathrm{ml}$ of filtrate $+0.5 \mathrm{ml}$ of benedict's reagent $\rightarrow$ heated on water bath for $2 \mathrm{~min}$. A characteristic colored ppt.

\section{Test for amino acids}

- Ninhydrin Test: Each crude extract solution (1 ml) was taken in a test tube, and a few drops of Ninhydrin reagent were added. A purple colour appeared, indicating the presence of amino acids.

\section{Test for glycosides}

- General test

Test A: Extract $200 \mathrm{mg}$ of drug with $5 \mathrm{ml}$ of dilute sulphuric acid by warming on a water bath. Filter it. Then neutralize the acid extract with $5 \%$ solution of sodium hydroxide. Add $0.1 \mathrm{ml}$ of Fehling's solution A and B until It becomes alkaline (test with $\mathrm{pH}$ paper) and heat on a waterfall for 2 minutes. Note the quantity of red precipitate formed and compare with that of formed in 'test B'.

- Test B: Extract $200 \mathrm{mg}$ of the drug using $5 \mathrm{ml}$ of water instead of sulphuric acid. After boiling add equal amount of water as used for sodium hydroxide in the above test. Add $0.1 \mathrm{ml}$ Fehling's solution A and B until alkaline (test with $\mathrm{pH}$ paper) and heat on water bath for 2 minutes. Note the quantity of red precipitate formed. Compare the quantity of precipitate formed in Test B with that of forms in Test A. If the precipitate in Test $\mathrm{A}$ is greater than in Test B then Glycoside may be present.

- Borntrager's test: To $3 \mathrm{ml}$ of test solution, dilute sulphuric acid was added, boiled for 5 minutes and filtered. To the cold filtrate, equal volume of benzene or chloroform was added and it was shaken well. The organic solvent layer was separated and ammonia was added to it. Formation of pink to red color in ammonical layer indicates the presence of anthraquinone glycosides.

- Keller-killiani test (Test for deoxy sugars): Extract the drug with chloroform and evaporate to dryness. Add 0.4 $\mathrm{ml}$ of glacial acetic acid containing trace amount of ferric chloride. Transfer to a small test tube, add carefully 0.5 $\mathrm{ml}$ of concentrated sulphuric acid by the side of the test tube. Acetic acid layer shows blue colour.

- Legal'stest: Treat the test solution with pyridine and add alkaline sodium nitroprusside solution. Red colour appears.

\section{Test for saponin}

- Froth formation test: Small amount of extract was shaken in a test tube with a little quantity of water.

\section{Test for steroid}

- Libermann-burchard's test: A few mg of the substance is dissolved in chloroform and acetic anhydride is added followed by sulphuric acid. Green colour indicates the presence of steroids.

\section{Tests for triterpenoids}

- Salkowski's test: The extract was treated with chloroform and filtered. The filtrate was added with few drops of concentrated sulphuric acid, shaken and allowed to stand. If the lower layer turns red, sterol is present. Presence of golden yellow layer at the bottom indicates the presence of triterpenes. 


\section{Test for flavonoids}

- Lead acetate test: To the alcoholic solution of the extract add few drops of lead acetate solution (10\%). A yellow ppt results.

- Shinoda test: To alcoholic test solution of extract add few fragments of magnesium ribbon. To this conc. $\mathrm{HCl}$ was added drop wise. Pink scarlet, crimson red or occasionally green to blue colour after few min.

- Zinc hydrochloride test: To the alcoholic test solution of the extract a pinch of zinc dust + conc. $\mathrm{HCl}$ few drops. Red colour/Megneta colour after few min.

\section{Tests for tannin and phenolic compounds}

- Ferric chloride test: A small amount of extract was dissolved in distilled water. To this solution $2 \mathrm{ml}$ of $5 \%$ ferric chloride solution was added. Formation of blue, green or violet color indicates presence of phenolic compounds.
- Dilute iodine solution test: To $2-3 \mathrm{ml}$ of extract, few drops of dilute iodine solution were added. Formation of transient red color indicates the presence of phenolic compounds.

\section{Results and Discussion}

The aqueous and methanolic extracts of Azadirachta indica and Andrographis paniculata when subjected to pharmacological analysis showed presence of various components (Table 1). These two medicinal plants contain active principles which are highly potent against parasites. Alkaloids, carbohydrate, amino acid, glycosides, saponin, steroid, flavonoid, tannin and phenolic compounds were present in all the four extracts. Anthraquinone glycosides was present only in the extracts of Azadirachta indica while Cardiac glycosides was present only in the methanolic extract of $A$. indica and triterpenoids were present only in methanolic extract of Andrographis paniculata in higher concentration.

Table 1: Phytochemical components present in the plant extracts

\begin{tabular}{|c|c|c|c|c|}
\hline Component & A. indica Aqueous & A. indica Methanol & A. paniculata Aqueous & A. paniculata Methanol \\
\hline Alkaloids & + & + & + & + \\
\hline Carbohydrate & + & + & + & + \\
\hline Amino acid & + & + & + & + \\
\hline Glycosides (general test) & + & + & + & + \\
\hline Anthraquinone glycosides & + & + & - & - \\
\hline Cardiac glycosides & - & $+^{*}$ & - & - \\
\hline Saponin & + & + & + & + \\
\hline Steroid & + & + & + & + \\
\hline Triterpenoids & - & - & - & $+^{*}$ \\
\hline Flavonoid & + & + & + & + \\
\hline Tannin and phenolic compounds & + & + & + & + \\
\hline
\end{tabular}

* Only in higher concentration, + Present; - Absent

Several workers suggested that the activity of many plant extracts did inhibit helminths but its effectiveness varied, probably due to the different chemical ingredients extracted in different solvents and to the source of parasites and previous exposure to the plants. The indigenous system of medicine reports a number of plants for their anthelmintic efficacy. Potential use of plant extracts as anthelmintics to control nematode parasites in small ruminants was suggested by several workers (Chagas et al., 2008 [4]; Aggarwal et al., 2015; Bauri et al., 2015) ${ }^{[3]}$. Kamaraj et al. (2011) ${ }^{[8]}$ assessed the efficacy of leaf, bark, and seed ethyl acetate, acetone and methanol extracts of Andrographis paniculata, Anisomeles malabarica, Annona squamosa, Datura metel and Solanum torvum by testing against the parasitic nematode of small ruminants $H$. contortus using egg hatch assay (EHA) and larval development assay (LDA) and found good result. A preliminary study carried out by Aggarwal et al. (2015) by phytochemical screening of three plant extracts (Calotropis procera, Azadirachta indica and Punica granatum) against Gastrothylax indicus also revealed presence of phenols, alkaloids, saponins, tannins, flavonoids, steroids and triterpenoids, having anthelmintic activity whose intensity varied among the plants and also with the solvent of extract. Azadirachta indica with active principle Azadirachtin, is a compound belonging to the limonoid group and is a secondary metabolite present in neem seeds. It is a highly oxidized tetranortriterpenoid which is rich in oxygen bearing functional groups, including enol ether, acetal, hemiacetal, tetra-substituted epoxide and a variety of carboxylic esters.

Similar study like us was carried out by Murali et al. (2014)

${ }^{[9]}$ wherein Andrographis paniculata was analyzed and found that anthelmintic effect may be attributed to the phytochemical constituents such as sterols and terpenes, polyphenols, flavonoids, tannins saponins, and alkaloids. Bauri et al. (2015) ${ }^{[3]}$ in their study using A. indica found that aqueous and methanolic extract of leaves of was effective against $H$. contortus, thus agreeing to our findings. Kamaraj et al. (2011) ${ }^{[8]}$ from their work concluded that A. paniculata plant may offer an alternative source for the control of gastrointestinal nematodes of sheep and goats. The mode of action of different phytochemical extracts was detailed by Bauri et al. (2015) ${ }^{[3]}$. Accordingly, alkaloids may act on central nervous system of the helminths and cause paralysis. Saponins affect the permeability of the cell membrane of parasites and cause vacuolization and disintegration of teguments while Phenolic compound and tannins interfere the energy generation of worms by uncoupling the oxidative phosphorylation and also interfere with the glycoprotein of the cell surface of the parasites and cause death. Tannins additionally or they binds to the free protein of the gastrointestinal tract of the host animal and lead to death. The phytochemical analyses of the effective plants and controlled anthelmintic trials along with contemporary knowledge of parasite control strategies may offer new opportunities for effective and economical control of parasitic diseases (Jabbar et al., 2006) ${ }^{[7]}$.

\section{Conclusion}

The aqueous and methanolic extracts of Azadirachta indica and Andrographis paniculata were found to have effective anthelmintic properties. Based on this, more detailed phytochemical analysis is required to isolate and characterize 
each active compound responsible for the anthelmintic activity and to understand their mechanisms of action.

\section{Acknowledgements}

The authors are grateful to the ICAR for granting the project, Head of the Department of Parasitology, CVSc, Khanapara, Guwahati and the team of Faculty of Pharmaceutical Science, Assam Down town University, Panikhaiti, Guwahati for their valuable help and necessary facilities provided during the study period.

\section{References}

1. Aggarwal R, Kaur K, Suri M, Bagai U. Anthelmintic potential of Calotropis procera, Azadirachta indica and Punica granatum against Gastrothylax indicus. Journal of Parasitic Diseases 2015:40(4):1230-1238.

2. Akhtar MS, Iqbal $Z$, Khan MN, Lateef $M$. Anthelmintactivity plants with particular reference to their use in animals inthe Indo-Pakistan subcontinent. Small Ruminant Reearch 2000;38:99-107.

3. Bauri RK, Tigga MN, Kullu SS. A review on use of medicinal plants to control parasites Indian Journal of Natural Products and Resources 2015;6(4):268-277.

4. Chagas ACS, Vieira LS, Freitas AR, Araujo MRA, Araujo-Filho JA, Araguao WR, Navarro AMC. Anthelmintic efficacy of neem (Azadirachta indica A. Juss) and thehomeopathic product Fator Vermes in Morada Nova sheep. Veterinary Parasitology 2008;151:68-73.

5. Exploring the anthelmintic properties of Australian native shrubs with respect to their potential role in livestock grazing systems

6. Iqbal $\mathrm{Z}$, Lateef $\mathrm{M}$, Jabbar $\mathrm{A}$, Gilani $\mathrm{AH}$. In vivo anthelmintic activity of Azadirachta indica A. Juss seeds against gastrointestinal nematodes of sheep. Veterinary Parasitology 2010;168:342-345.

7. Jabbar A, Raza MA, Iqbal Z, Khan MN. An inventory of the ethnobotanicals used as anthelmintics in the southern Punjab (Pakistan) Journal of Ethnopharmacology 2006;108(1):152-154.

8. Kamaraj C, Rahuman AA, Elango G, Bagavan A, Zahir AA. Anthelmintic activity of botanical extracts against sheep gastrointestinal nematodes, Haemonchus contortus. Parasitology Research 2011;109:37-45.

9. Murali J, Maheswari R, Muzammil MS, Asogan G. Anthelmintic activity of leaves extract of Andrographis paniculata Nees. International Journal of Pharmacognosy 2014;1(6):404-08.

10. Mutheea JK, Gakuyaa DW, Mbariab JM, Kareruc PG, Muleia CM. Njonge FK. Ethnobotanical study of anthelmintic and other medicinal plants traditionally used in Loitoktok district of Kenya. Journal of Ethnopharmacology 2011;135:15-21.

11. Sharma LD, Bahga HS, Srivastava PS. In-vitro anthelmintic screening of indigenous plants against Haemonchus contortus in sheep and goats. Indian Journal of Animal Research 1971;5:33-38.

12. Susmitha S, Vidyamol KK, Ranganayaki P, Vijayaragavan R. Phytochemical Extraction and Antimicrobial Properties of Azadirachta indica (Neem). Global Journal of Pharmacology 2013;7(3):316-320.

13. Yadav P, Singh R. A review on anthelmintic drugs and their future scope. International Journal of Pharmacy and Pharmaceutical Sciences 2011;3(3). 